\title{
DETECTION OF TRANSMISSION SYSTEM OF CONSTRUCTION MACHINERY BASED ON VIRTUAL TECHNOLOGY
}

\author{
Liping $L v^{1}$ \\ ${ }^{1}$ Department of mathematics and information Engineering, Henan University Puyang \\ Institute of Engineering, Henan, Puyang, 457000, China. \\ Email: lvlipinggo111@126.com
}

\begin{abstract}
In order to apply virtual prototyping technology to the transmission system of construction machinery, shorten the test cycle effectively and save energy, a virtual test system of hydraulic mechanical transmission of construction machinery is established by using Visual C++ programming technology and ADAMS virtual prototyping technology. The composition of the hydraulic mechanical transmission system of construction machinery and the performance characteristics of its components, as well as the test method of the hydraulic mechanical transmission system, the matching principle between engine and hydraulic torque converter are analyzed. Additionally, the man-machine interaction interface of the virtual test system of hydraulic mechanical transmission of construction machinery is designed with Visual C++ software. According to the test that the virtual test system needs to complete and the parameters that each test needs to set, the design of human-computer interaction interface of the virtual test system of hydraulic mechanical transmission is completed by adding various controls to the Visual $\mathrm{C}++$ software programming interface; the model of hydraulic torque converter and gearbox in the hydraulic mechanical transmission system is established by using ADAMS virtual prototype technology, and the diesel engine model is established at the same time. The attribute files and model parameters of each part of the transmission system are modified to make the performance of each part in the virtual test system consistent with that of the transmission system components to be tested. The results show that a complete virtual simulation test system for hydraulic chassis of construction machinery is established through the above analysis and research. Therefore, the research will play a guiding and reference role in the scientific research of hydraulic chassis test of construction machinery.
\end{abstract}

Keywords: Virtual Experiment; Construction Machinery; Mechanical Transmission; System Testing.

\section{Introduction}

In modern engineering construction, with the investment of various construction machinery, human beings have not been required to participate in various construction projects through their own hands as before, but began to operate various construction machinery for engineering construction. Human direct labour has gradually been replaced by construction machinery [1].

Engineering machinery and equipment has become an important force in engineering construction. Nowadays, with the rapid development of science and technology, engineering machinery and equipment is developing in the direction of large-scale, high-speed, complex, continuous and automation.

As a result, engineering machinery and equipment becomes more and more complex, it has more and more powerful, more and more large-scale equipment, and higher and higher equipment productivity, and it is more and more widely used in engineering construction.

With the rapid development of China's construction machinery, improving the performance of construction machinery and saving energy is an urgent issue to be solved. In order to verify the mechanical properties and optimize the design, a large number of related mechanical performance tests are needed. Therefore, a large number of construction machinery test benches are set up. Because repeated tests are needed and the test cycle is long, this will inevitably result in waste of energy. Based on the development of computer technology and modern computing methods, virtual prototyping technology has made great progress.

Virtual prototyping technology in mechanical engineering mainly refers to the kinematics and 
dynamics analysis of mechanical system. Its core is to use computer technology to carry out kinematics and dynamics analysis of mechanical system to determine the position, speed and acceleration of system and components at any time. At the same time, the action force and reaction force needed to cause the motion of the system and its components are determined by solving the algebraic equations.

\section{Literature Review}

At present, the development speed of construction machinery is astonishing, and more and more advanced construction machinery is needed to serve human construction and production activities. Under this background, domestic and foreign researchers have made more achievements in the evaluation and fault diagnosis of construction machinery through unremitting efforts. In 2016, Maré studied the electric drive mechanical transmission system which combines the motor with the mechanical transmission system.

The system follows the principle of power transmission integration and verifies the superiority of the three-level EMT system in terms of efficiency and fuel economy [2]. In 2015, Xu et al. established a three-dimensional model of hydraulic components, introduced the working principle of hydraulic components, and simulated the operation process and performance of hydraulic circuit [3]. In 2016, Zhang et al. established a virtual hydraulic test system with its own characteristics.

The virtual experiment system is not only suitable for classroom teaching, but also for experimental teaching. The use of the system improves students' learning enthusiasm [4]. In 2016, Chen and Tian designed an electronic automatic transmission test data acquisition system based on virtual instrument. Data acquisition system can collect data including automatic transmission oil pressure, duty cycle of solenoid valve and CAN information from automatic transmission and engine control unit [5]. In 2016, Saulescu et al. proposed a new type of hydraulic electromechanical transmission system to meet the starting and speed regulation requirements of high-power equipment. The system has the functions of soft start, stepless speed regulation, soft stop, self-weight down-stroke controllability, overload protection, explosion-proof and so on [6]. In 2015, Zhai et al. proposed a virtual prototype modelling method of hydraulic torque converter, shift clutch and vehicle transmission system with locking function. According to the structure and principle of hydraulic mechanical transmission system widely used in vehicle transmission, the model was analyzed and the dynamic model was established [7].

In 2018, in order to predict the performance of vehicle transmission system in the design stage, Chen et al. validated the virtual prototype model according to the power input characteristics and working mode of the start-up process test.

The comparison of simulation and test results shows that the virtual prototype model is correct and reasonable, and has high accuracy [8].

\section{Method}

Construction machinery mainly transforms the chemical energy of engine fuel into mechanical energy through the engine in power system, and transforms mechanical energy into hydraulic energy of hydraulic system through hydraulic pump. Then, it transforms hydraulic energy into mechanical energy again through hydraulic motor and hydraulic cylinder in hydraulic system to realize the movement of working device of construction machinery, normal work of electronic control system, normal movement of working platform, walking and movement of walking device, etc.

The evaluation of construction machinery is just like a doctor's physical examination of a patient. Whether the results of the examination are normal or not depends on whether the parameters of the examination meet the criteria. Therefore, the detection and evaluation of construction machinery is closely combined with the fault diagnosis of construction machinery. Detection and evaluation should be based on fault diagnosis. Without the data collected from fault diagnosis as support, detection and evaluation will not have much significance. The composition of the detection and evaluation system for construction machinery is shown in Figure 1.

There are many kinds of sensors, and the structure and principle are also varied. When establishing the detection system, it is necessary to select the appropriate sensor to build the detection system according to the needs of the detection object.

When the type of sensor is determined, the measurement system matching the sensor is determined. In other words, the choice of sensors is the primary task of building a hardware part of the test system. 


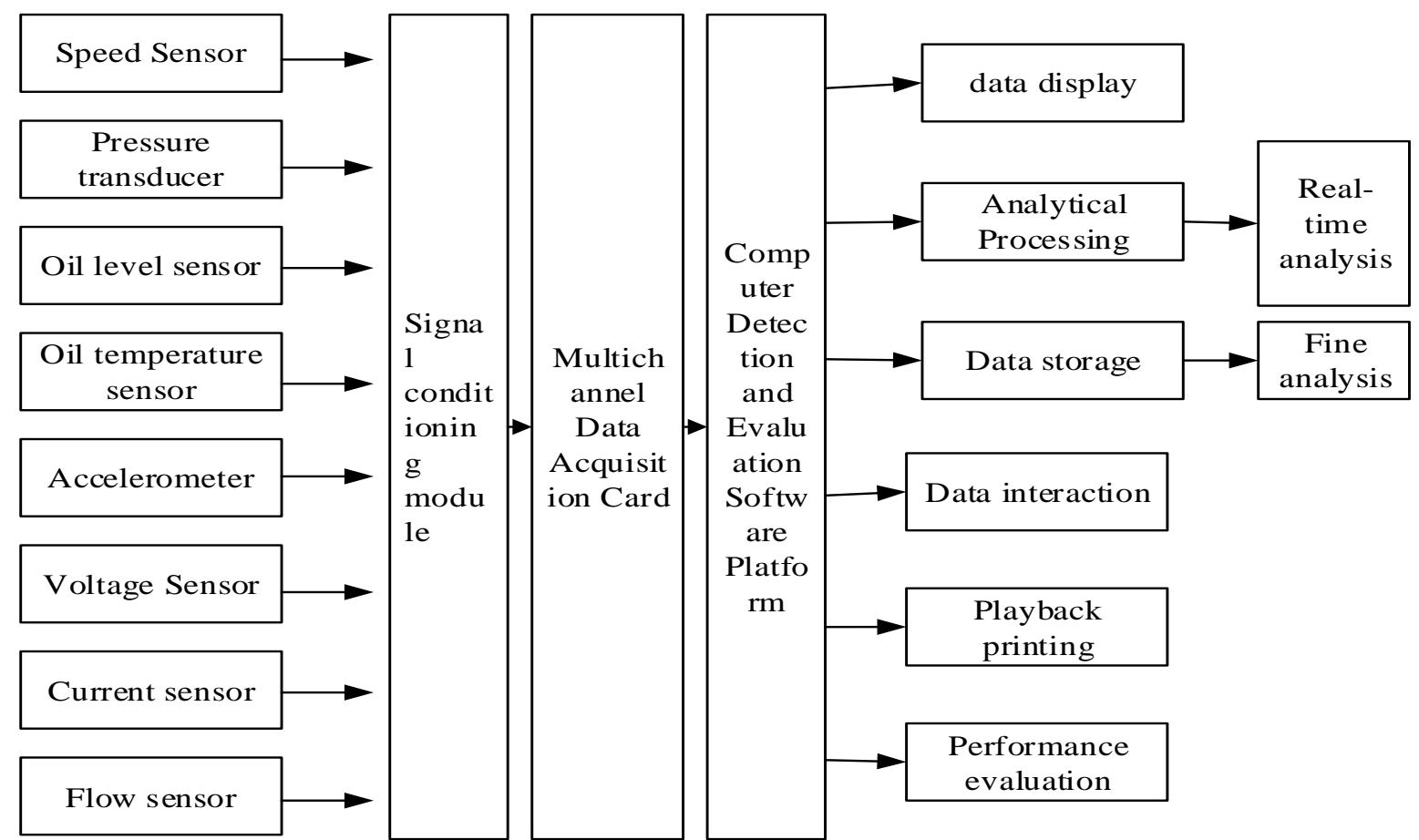

Figure 1: General system diagram of detection and evaluation of construction machinery

The performance of this primary task can directly affect the follow-up tasks and test results. Therefore, according to the actual situation of the test object, the sensor should be selected reasonably according to the national standard.

The sensors selected by the system and the parameters measured by them are shown in Table 1 .

Table 1. Types of sensors and their measuring

\begin{tabular}{|l|l|}
\hline Sensor types & Measurement object \\
\hline Speed sensor & Flywheel speed \\
\hline $\begin{array}{l}\text { Clamping pressure } \\
\text { sensor }\end{array}$ & $\begin{array}{l}\text { Hydraulic system } \\
\text { pressure }\end{array}$ \\
\hline Accelerometer & vibration acceleration \\
\hline speed sensor & vibration velocity \\
\hline Temperature sensor & $\begin{array}{l}\text { Oil temperature and } \\
\text { water temperature }\end{array}$ \\
\hline $\begin{array}{l}\text { Voltage and current } \\
\text { transformers }\end{array}$ & $\begin{array}{l}\text { Voltage and current of } \\
\text { starting motor }\end{array}$ \\
\hline
\end{tabular}

Because the hydraulic transmission has no fixed transmission ratio, it can realize stepless speed regulation and constant power output control; the overall structure of the hydraulic transmission device is very compact, so under the same power conditions, its transmission system is relatively small in volume, and has flexible and changeable components layout; the hydraulic transmission device has high speed rigidity, good adaptability to external loads, and stable system.

The hydraulic transmission system can easily realize overload protection, play a role of safety protection, and make the automatic control of the system faster. Therefore, hydraulic transmission is widely used in engineering machinery to control and regulate.

The following figure is a typical composition of the hydraulic transmission system.

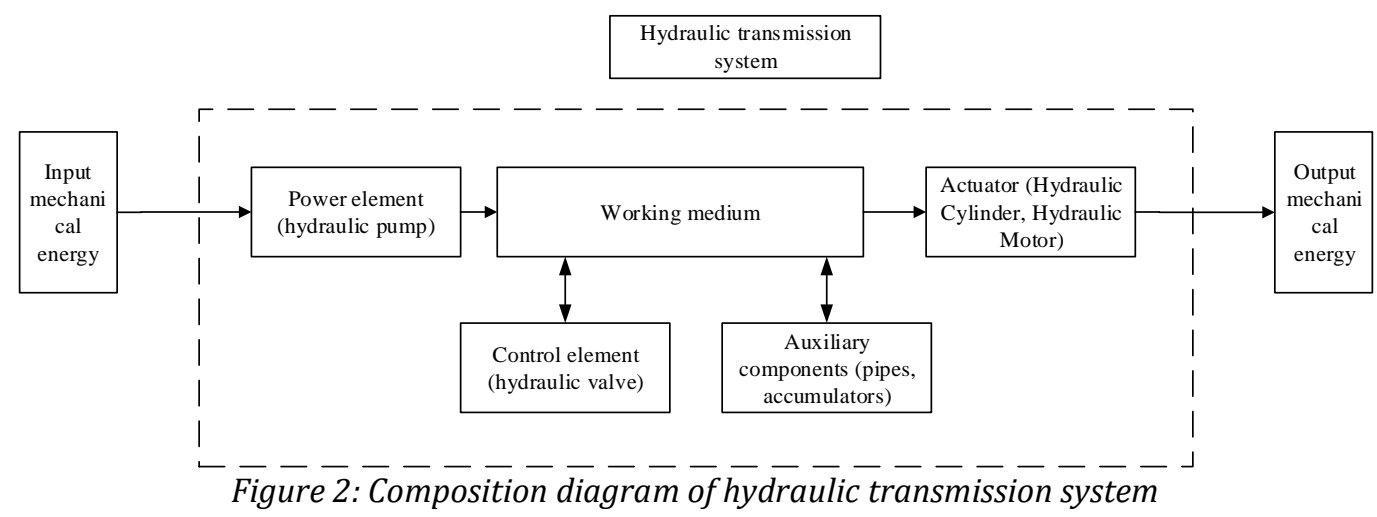




\section{Results and discussion}

\subsection{Composition and test method of hydraulic mechanical transmission test system}

In the hydro-mechanical transmission system of construction machinery, the power of engine usually passes through the hydraulic torque converter, gearbox, transmission shaft, differential, wheel-side reducer, etc., and the hydraulic torque converter and gearbox play a vital role in the performance of the transmission system. Therefore, the hydromechanical transmission test-bed mainly studies the influence of the hydraulic torque converter and gearbox on the performance of the whole machine. As the power source of construction machinery, diesel engine plays a decisive role. The transmission system only transmits the power of the engine to the walking mechanism and working device in the most effective way. Therefore, it is necessary to know the relevant characteristics of the engine before studying the transmission system. Diesel engine characteristics mainly include load characteristics, speed characteristics and speed control characteristics.

The external characteristics of hydraulic torque converter usually refer to the relationship between the input torque $\mathrm{M}_{\mathrm{B}}$, output torque $\mathrm{M}_{\mathrm{T}}$, efficiency factor $\eta$ and the turbine speed $n_{T}$ of the converter when the pump wheel speed $n_{B}$ is fixed. From the external characteristic curve of the centripetal turbine torque converter, it is known that the efficiency curve of the hydraulic torque converter is parabolic, and the maximum efficiency $\eta_{\max }$ is 0.8 0.9 . It is usually required that the hydraulic torque converter works in the range of $\eta>0.75$, that is, the turbine speed is in the $\mathrm{n}_{\mathrm{TI}}-\mathrm{n}_{\mathrm{T} 2}$ range. The wider the efficiency zone is, the wider the corresponding range of the economic operation of the torque converter will be. When $\mathrm{M}_{\mathrm{B}}=-\mathrm{M}_{\mathrm{T}}$, the hydraulic torque converter enters the working condition of the coupling. As shown in point A in Figure 3, the efficiency decreases greatly at this time, which should be avoided in practical application.

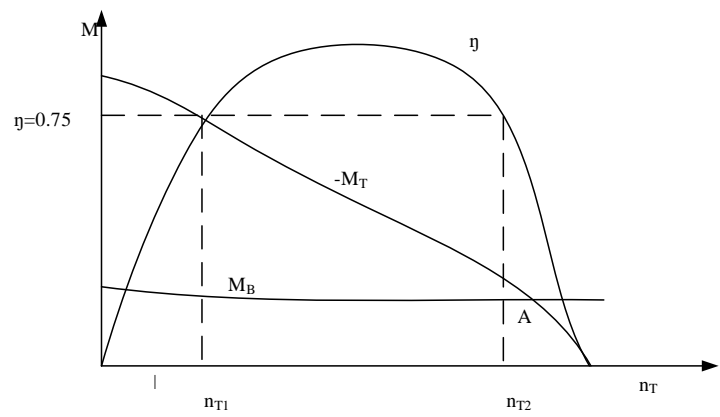

Figure 3: External characteristics of centrifugal turbine torque converter
The input characteristic of the hydraulic torque converter is the relationship between the speed $n_{B}$ of the pump wheel and the torque $\mathrm{M}_{\mathrm{B}}$ of the pump wheel.

$\mathrm{M}_{\mathrm{B}}=\lambda_{\mathrm{B}} \rho \operatorname{gn}_{\mathrm{B}}^{2} \mathrm{D}^{5}$

Formula (1) shows that $M_{B}$ is a quadratic function of $\lambda_{B}$, that is, the input characteristic of the hydraulic torque converter is a parabola. From the original characteristics of the hydraulic torque converter, it can be seen that $\lambda_{B}$ is the function of transmission ratio $i$, namely $\lambda_{B}=f(i)$. Therefore, for different transmission ratio $i$, there are different input characteristic curves. As a result, the input characteristic curve of the hydraulic torque converter is composed of many parabolas corresponding to different transmission ratio i.

The input characteristic curve group of the penetrating hydraulic torque converter is shown in Figure 4.

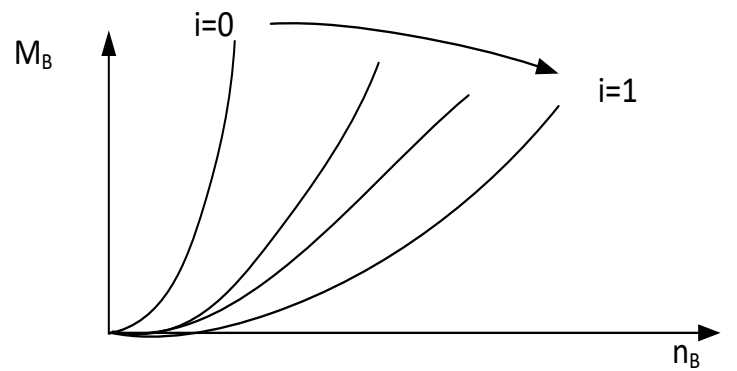

Figure 4: Input characteristics of positive penetration torque converter

\subsection{Design of virtual test system}

The virtual test system should be able to simulate the working process of the hydro-mechanical transmission system and analyze the characteristics of the components and the common working characteristics. Virtual test system should achieve the following functions: first, setting parameters and drawing test curves.

Before the test, the type of hydraulic torque converter and engine to be tested can be selected, the transmission ratio of gearbox can be set, and the driving and load form and size can be set.

Second, the function of simulation and analysis. It can be used for traction performance simulation test and efficiency test of each sub-component of hydromechanical transmission system, and matching characteristics of engine, torque converter and gearbox working together.

Third, results. After the simulation, the simulation results can be displayed in the form of curves and data charts, and the simulation animation can be output.

Fourth, data output. The simulation results can be saved in the form of pictures and excel tables. There are many test items, parameter setting and data 
output items in the virtual test system of construction machinery and hydraulic machinery.

According to the design method of function division module, the hydraulic torque converter test, gearbox test and matching test are divided into three separate modules.

The three modules can perform the functions of test parameter setting, simulation test, curve and animation viewing and data output separately.

The overall design framework is shown in Figure 5.

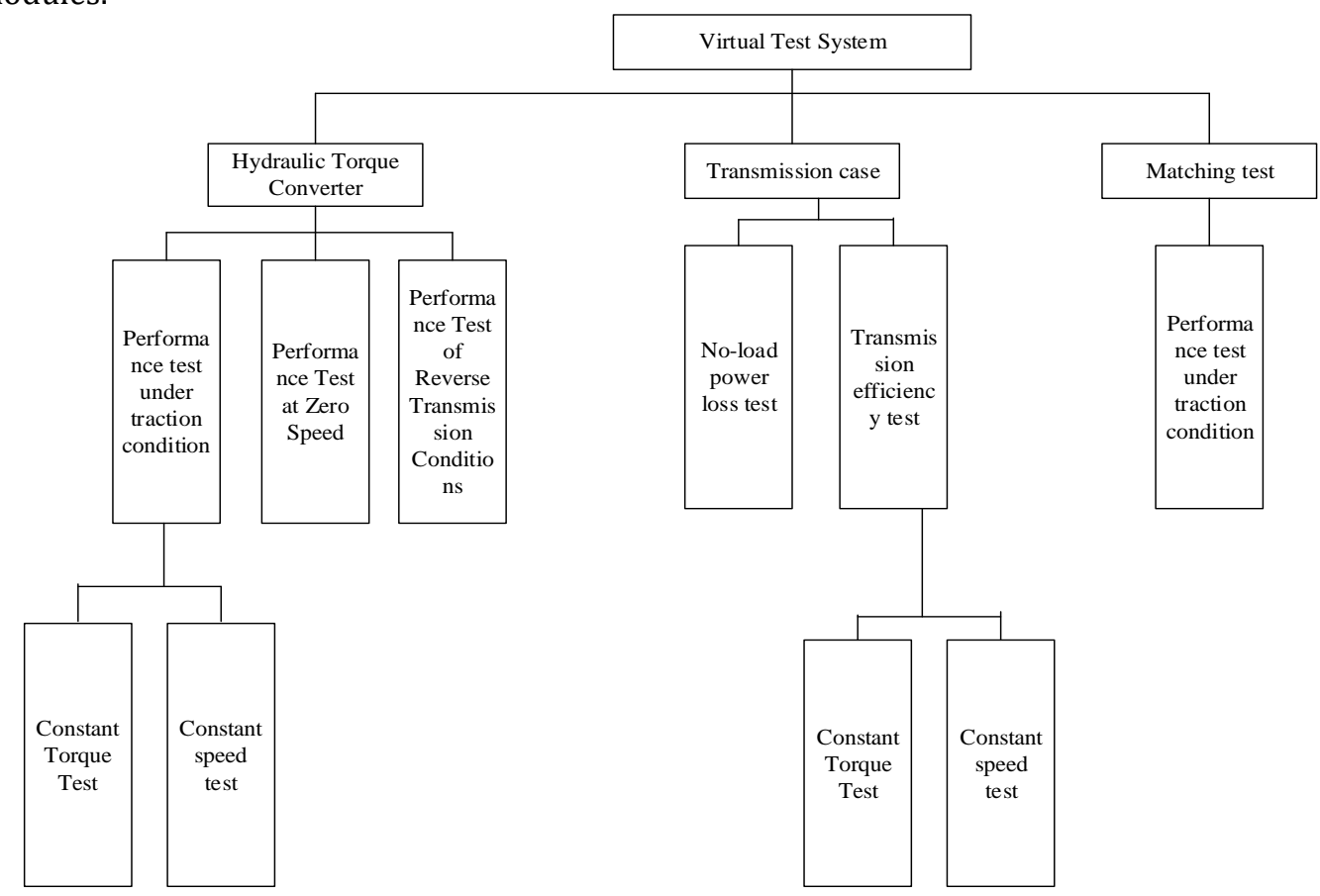

Figure 5: Overall framework of virtual test system

\subsection{Establishment of test system in ADAMS software}

ADAMS software is the most widely used dynamic simulation tool of mechanical system in the world, which has complete analysis tools. It enables engineers to build virtual prototype of mechanical system, analyze its performance, better understand the movement of mechanical system, compare various design schemes, accurately predict load changes, and calculate the properties of motion trajectory, speed and acceleration.

In ADAMS, it is very convenient to establish the virtual test system of transmission system. First, the power source model, that is, the engine model, is needed. Then, the main components of transmission system, including hydraulic torque converter, transmission and other components, are established in ADAMS software. At the same time, the test bench is established to test and output the simulation test data.

ADAMS/Driveline is the next module of ADAMS software specially used for transmission modelling and simulation and it is a supplement to ADAMS/Car. It works with ADAMS/Car and can be regarded as a plug-in of ADAMS/Car module. Like ADAMS/Car, the model is based on template modelling. The module has templates such as engine, gearbox, transmission shaft and differential, and can build its own template under Template Builder to form user's own template library. Template is a parameterized model and it contains part parameters and topological structure of standard model components. With these templates, different subsystems can be generated by modifying parameters such as size, mass, material, moment of inertia and position. That is, a template covers many similar subsystems, and similar subsystems can be built quickly according to the template. In this way, subsystems can be set up quickly and accurately through the template, and mechanical systems can be tested. Time can be saved in order to improve the design and obtain better design results.

At the same time, after building subsystems through these templates, these subsystems can be assembled into assembly components according to the requirements. After assembly, any subsystems can be easily replaced without changing other parts of the system, and the influence of different subsystems on the mechanical system can be quickly tested.

\subsection{Test process and analysis of virtual test system}

In ADAMS/Driveline software, the hydraulic mechanical transmission system is a simplified model, which simplifies some factors that have little influence on the simulation results. Before the simulation, it is considered that the engine model, 
the hydraulic torque converter model, the gearbox model and the assembly model of the transmission system are fixed on the ground, and that the assembly clearance of each component is zero relative to the ground. Neglect the dimension manufacturing error and neglect the fluid interaction in slightly hydraulic torque converter. Ignore bearing parts and replace them with rotating pairs. Ignore bolt connection and coupling connection.

When simulating in ADAMS/Driveline software, the appropriate integrator should be selected according to the simulation solution. The default integrator of the software is GSTIFF, and the GSTIFF integrator is a rigid stability algorithm. It adopts multi-step, variable-order, variable-step and fixedcoefficient algorithm. Differential equation (DAE) can be solved directly. Taylor series is used in the prediction. The highest order is 6, and the asymptotic stability condition is satisfied only when the highest order is less than or equal to 6 . This algorithm has fast calculation speed and high displacement precision, and can be combined with I3, SI2 and SI1 to adapt to many simulation and analysis problems. Generally, three integration methods, GSTIFF, WSTIFF and CONSTANT_BDF, are used. These three integration methods are all rigid stability algorithms. They adopt multi-step and variable-order algorithms, and all have three stability indices I3, SI2 and SIl.

Table 2 shows the comparison of several integrators in algorithm mechanism, solution speed and stability.

\section{Table 2. Integrator comparison}

\begin{tabular}{|c|c|c|c|c|c|}
\hline & Algorithm & $\begin{array}{c}\text { Highest } \\
\text { order }\end{array}$ & $\begin{array}{c}\text { Dead } \\
\text { reckoning }\end{array}$ & Solving speed & $\begin{array}{c}\text { Optional } \\
\text { stability } \\
\text { index }\end{array}$ \\
\hline GSRIFF & $\begin{array}{c}\text { Rigidity, multi-step, } \\
\text { variable order }\end{array}$ & 6.6 & $\begin{array}{c}\text { Taylor } \\
\text { series }\end{array}$ & Fast & I3/SI2/SIl \\
\hline WSTIFF & $\begin{array}{c}\text { Rigidity, multi-step, } \\
\text { variable order }\end{array}$ & 6.6 & NDF & Commonly & I3/SI2/SIl \\
\hline CONSTANT_BDF & $\begin{array}{c}\text { Rigidity, multi-step, } \\
\text { variable order }\end{array}$ & 6.6 & NDF & Fast & I3/SI2/SIl \\
\hline ABAM & $\begin{array}{c}\text { Non-rigid, multi-step, } \\
\text { variable order }\end{array}$ & 13.2 & -- & Commonly & -- \\
\hline RKF45 & Single step & 13.2 & -- & Slow & - \\
\hline
\end{tabular}

The core of the virtual test system of hydraulic machinery is to operate in the human-computer interface during the test, which is carried out in ADAMS/Driveline software. Each test of virtual test system adopts single assembly bench test. Driving and loading are realized by establishing power elements on input and output axes. The power elements are established on input axes and output axes respectively for hydraulic torque converter test and gearbox test. The power elements are used to drive and load the model, and the relevant test parameters are set up before the virtual test bench is carried out.

After the virtual simulation is finished, the postprocessing program is checked, and the simulation results are transferred through the human-computer interaction interface operation, and the test data and animation are output.

\section{Conclusion}

Relying on the school comprehensive transmission test-bed, using Visual $\mathrm{C}++$ software for interface programming, ADAMS/Driveline establishes a virtual prototype model. Through programming in the operation interface call, a good virtual prototype model is set up, and the two together constitute a virtual test system for hydraulic mechanical transmission of construction machinery. Summarizing the work done here, the following conclusions are obtained:

At present, the development of evaluation technology for construction machinery in China is far from meeting the needs of evaluation technology for construction machinery. The trade of second-hand construction machinery is also affected by the constraints of evaluation technology of construction machinery.

The characteristics of hydraulic torque converter, gearbox and diesel engine of hydraulic mechanical transmission system are analyzed, as well as the test methods and specifications of each component of transmission system. When designing the virtual test system, the test specifications of each component of transmission system are complied with.

The virtual test system can complete all the tests as the actual transmission test bench. A virtual test system for hydraulic mechanical transmission of construction machinery is established and the virtual experiment analysis is carried out.

The virtual test analysis shows that the traction performance test, zero speed performance test, reverse transmission performance test, no-load power loss test of gearbox, transmission efficiency test, matching test of traction performance between 
engine and hydraulic torque converter can be realized, and the corresponding characteristic curve and simulation animation of each test can be output.

\section{References}

[1] Ma, J. P., Chen, W., Zhong, J. (2015). The Testing System of Precise Motion Transmission Chains Based on Virtual Instrument. Applied Mechanics \& Materials, 775, 385-389.

[2] Maré, J. C. (2016). Requirement-based systemlevel simulation of mechanical transmissions with special consideration of friction, backlash and preload. Simulation Modelling Practice \& Theory, 63, 58-82.

[3] Xu, J. L., Yan, T., Peng, B. (2015). Effects of the transmission shaft on the main reducer vibration based on ADAMS and experimental demonstration. Australian Journal of Mechanical Engineering, 15(1), 1-9.

[4] Zhang, L., Ren, Z., Sun, S. (2016). Research on Dynamic Load and Stress of High-speed EMU
Motor Hanger Considering Influence of Gear Transmission System. Journal of Mechanical Engineering, 52(4), 133-140.

[5] Chen, H., Tian, G. (2016). Modeling and analysis of engaging process of automated mechanical transmissions. Multibody System Dynamics, 37(4), 345-369.

[6] Saulescu, R., Jaliu, C., Neagoe, M. (2015). On a New Chain Planetary Transmission for Renewable Energy Systems - Part II: Virtual Prototyping and Experimental Testing. Applied Mechanics \& Materials, 760(1), 153-158.

[7] Zhai, H., Zhu, C., Song, C (2015). Dynamic modeling and analysis for transmission system of high-power wind turbine gearbox. Journal of Mechanical Science \& Technology, 29(10), 4073-4082.

[8] Chen, X., Song, C., Zhu, C. (2018). Effects of macro-parameters on vibration and radiation noise for high speed wheel gear transmission in electric vehicles. Journal of Mechanical Science and Technology, 32(9), 4153-4164. 